\title{
Double blind controlled trial of d-penicillamine in patients with primary biliary cirrhosis
}

\author{
J NEUBERGER, E CHRISTENSEN, B PORTMANN, J CABALLERIA, J RODES, \\ L RANEK, N TYGSTRUP, AND ROGER WILLIAMS \\ From the Liver Unit, King's College Hospital and Medical School, London, Hvidovre Hospital, \\ Copenhagen, Denmark, Hospital Clinic i Provencial, Barcelona, Spain, and Rigshospitalet, Copenhagen, \\ Denmark
}

SUMMARY One hundred and eighty nine patients with primary biliary cirrhosis were entered into a double blind, placebo controlled randomised trial starting in January 1978 to assess the therapeutic value of d-penicillamine $1200 \mathrm{mg}$ daily. Eighteen of the 98 patients receiving d-penicillamine and 22 of the 91 placebo treated patients died during the study. Thirty six per cent of those on d-penicillamine and $8 \%$ of those on placebo were withdrawn from the study. No difference in overall survival was noted between the two groups of patients whether the results were analysed for the entire period of observation or only during the period in which the patients were receiving therapy. The mortality rate of those receiving d-penicillamine in histological stage I to II, however, was one third of that of the placebo group although this difference did not reach statistical significance. Using the occurrence rate ratio as the statistical method of analysis, no effect of d-penicillamine was noted on any clinical, biochemical or histological features examined, except the serum alanine aminotransferase activity which was greater in those on active treatment. In this trial we have been unable to establish any therapeutic benefit from the drug.

A number of therapeutic agents have been used in an attempt to control the underlying lesion in primary biliary cirrhosis. Corticosteroids have been associated with improvement of serum liver function tests, ${ }^{12}$ but no controlled trial has been carried out and their bone thinning properties are likely to exacerbate the osteoporosis associated with the disease. $^{3}$ In one large multicentre placebo controlled trial azathioprine appeared to have some effect although the difference in survival did not reach statistical significance. ${ }^{4}$ d-penicillamine was used initially because of its cupruretic effect ${ }^{5}$ and its ability to remove immune complex-like activity from the serum of such patients. ${ }^{6}$ It is now apparent, however, that the drug has other properties which may affect the course of primary biliary cirrhosis, such as its ability to interfere with collagen metabolism ${ }^{7}$ and to reduce the number of circulating T lymphocytes. ${ }^{8}$ After the publication of a preliminary study suggesting that survival was improved, ${ }^{9}$ a

Address for correspondence: Dr J Neuberger, Liver Unit, King's College Hospital and Medical School, Denmark Hill, London SE5 8RX.

Received for publication 2 March 1984 number of controlled trials were set up, but the results to date are conflicting. ${ }^{10-13}$ We report here the results of an international, double blind, placebo controlled trial set up in 1977.

\section{Methods}

\section{PATIENTS}

Criteria for entry into the trial included a clinical and histological picture compatible with that of primary biliary cirrhosis, the liver biopsy being taken within six months before entry and a serum alkaline phosphatase more than twice the upper limit of normal in the absence of evidence of extrahepatic biliary obstruction. Those patients who had been taking azathioprine within six months were excluded from the study. Informed consent was obtained before entry into the study and approval was also given by the ethical committee in each hospital.

Patients were entered regardless of age or histological stage of the disease at diagnosis. Randomisation was performed separately for each Centre 
(London, Barcelona, Copenhagen) and for each sex. Dosage was one tablet daily (containing either d-pencillamine $300 \mathrm{mg}$ or lactose $50 \mathrm{mg}$ ), being increased by one tablet each fortnight until a maximum of four tablets daily were taken. In addition, all patients were given pyridoxine $20 \mathrm{mg}$ daily. Patients were withdrawn from the trial if they developed signs or symptoms of possible side-effects from d-penicillamine, specifically thrombocytopenia (less than $60 \times 10^{9} / 1$ ), neutropenia (less than $2 \times 10^{6} / 1$ ) or proteinuria (greater than $2 \mathrm{~g}$ daily).

Clinical assessment was carried out at entry and at six monthly intervals. This included an estimation of the patient's well-being, as assessed by the incapacitation index described in detail elsewhere. ${ }^{4}$ Blood was taken for estimation of standard liver function tests, serum immunoglobulins and autoantibodies. Each patient underwent a liver biopsy within six months of entry into the trial and at annual intervals. The biopsy specimens were assessed by a histopathologist (BP), without knowledge of treatment received or clinical condition of the patient.

\section{STATISTICAL ANALYSIS}

The death rate and the occurrence rate of clinical, serological, and histological features in patients who did not have those features at entry into the trial were analysed by the life table method using the log rank test for comparison of groups. ${ }^{14}$ This method was used because it allows for incomplete follow up whether because of death, withdrawal, or loss from follow up. The occurrence rate ratio (or relative risk) was calculated as $\left(\mathrm{O}_{\mathrm{PEN}} / \mathrm{E}_{\mathrm{PEN}}\right) /\left(\mathrm{O}_{\mathrm{PLAC}} / \mathrm{E}_{\mathrm{PLAC}}\right)$ when $\mathrm{O}_{\mathrm{PEN}}$ is the number of patients observed to develop a particular abnormal feature on d-penicil- lamine and $E_{P E N}$ is the estimated number of patients in the d-penicillamine treated group expected to develop that feature. $\mathrm{O}_{\mathrm{PLAC}}$ and $\mathrm{E}_{\mathrm{PLAC}}$ are the corresponding values for the placebo treated group. The calculation of $E_{P E N}$ and $E_{P L A C}$ uses the temporal pattern of occurrence and assumes that the rate of occurrence is the same in the two groups; ${ }^{4}$ hence a ratio of 0.5 means that the feature is half as likely to occur in the treated group as in the placebo group. Because this method requires that continuous variables, such as serum bilirubin, are analysed as discrete ones, we have arbitrarily chosen to define an occurrence if the value falls outside the 'abnormal' fifteenth percentile of the distribution of that variable at entry. Thus, with respect of serum bilirubin, an occurrence was deemed to occur when the serum concentration exceeded $90 \mu \mathrm{mol} / \mathrm{l}$; and other limits are given in Table 1. Analyses were performed both for the total period of observation and up to the time of withdrawal.

\section{Results}

Between January 1978 and December 1982 when this analysis was performed, 189 patients had been entered into the trial. Of the total, 87 had been followed in London, 65 in Copenhagen and 37 in Barcelona. Analysis of the clinical, biochemical, serological, and histological data for patients in the d-penicillamine treated and placebo treated groups were similar at entry (Table 2). Nine patients receiving d-penicillamine were asymptomatic at the time of entry into the trial and eight in the placebo group.

In the d-penicillamine treated group 35 were withdrawn from treatment, because of rash (9),

Table 1 Effect of d-penicillamine on the occurrence rate of clinical, biochemical and histological features after entry into the trial

\begin{tabular}{|c|c|c|c|c|}
\hline \multirow[b]{2}{*}{ Variable } & \multicolumn{2}{|c|}{ Observed/expected ratio } & \multirow{2}{*}{$\begin{array}{l}\text { Occurrence rates ratio } \\
\text { (95\% confidence limits) }\end{array}$} & \multirow{2}{*}{$\begin{array}{l}p \text { Value } \\
(2 \alpha)\end{array}$} \\
\hline & $d$-penicillamine & Placebo & & \\
\hline \multicolumn{5}{|l|}{ Clinical features } \\
\hline Pruritus/cholestyramine & $16 / 13 \cdot 03$ & $26 / 28 \cdot 97$ & $1.37(0.77-2 \cdot 42)$ & $0 \cdot 78$ \\
\hline Ascites/diuretics & $14 / 15 \cdot 74$ & $21 / 19 \cdot 26$ & $0.82(0.45-1 \cdot 50)$ & $0 \cdot 52$ \\
\hline GI bleeding & $4 / 4 \cdot 81$ & $8 / 7 \cdot 19$ & $0.75(0 \cdot 26-2 \cdot 14)$ & 0.59 \\
\hline Incapacitation index $>25$ & $22 / 22 \cdot 74$ & $24 / 23 \cdot 26$ & $0.94(0.54-1.64)$ & 0.83 \\
\hline \multicolumn{5}{|l|}{ Biochemistry } \\
\hline Bilirubin $>90 \mu \mathrm{mol} / \mathrm{l}$ & $7 / 10 \cdot 30$ & $14 / 10 \cdot 70$ & $0 \cdot 52(0 \cdot 21-1 \cdot 26)$ & $0 \cdot 15$ \\
\hline Albumin $<30 \mathrm{~g} / 1$ & $13 / 14 \cdot 80$ & $16 / 14 \cdot 20$ & $0.78(0.38-1 \cdot 61)$ & $0 \cdot 50$ \\
\hline $\operatorname{IgM}>6.9 \mathrm{~g} / 1$ & $15 / 11 \cdot 14$ & $14 / 17 \cdot 86$ & $1 \cdot 72(0 \cdot 91-3 \cdot 25)$ & $0 \cdot 09$ \\
\hline \multicolumn{5}{|l|}{ Histology } \\
\hline Stage III/IV & $21 / 17 \cdot 75$ & $13 / 16 \cdot 26$ & $1 \cdot 48(0 \cdot 77-2 \cdot 86)$ & $0 \cdot 24$ \\
\hline Stage IV & $10 / 11 \cdot 35$ & $13 / 16 \cdot 23$ & $0.79(0.35-1.76)$ & 0.56 \\
\hline
\end{tabular}

Bilirubin $1 \mu \mathrm{mol} / \mathrm{l}=0.02 \mathrm{mg} / \mathrm{dl}$. Albumin $1 \mathrm{~g} / \mathrm{l}=0.1 \mathrm{~g} / \mathrm{dl}$. 
Table 2 Clinical, median biochemical, serological and histological details of patients in the placebo and $d$-penicillamine groups at entry into the trial

\begin{tabular}{|c|c|c|}
\hline & Placebo & d-penicillamine \\
\hline Cases (no) & 91 & 98 \\
\hline Males (\%) & 7 & 9 \\
\hline Median duration of history (years) & $1 \cdot 6$ & $1 \cdot 8$ \\
\hline \multicolumn{3}{|l|}{ Frequency of clinical findings } \\
\hline Pruritus & $63 \%$ & $59 \%$ \\
\hline Jaundice & $46 \%$ & $37 \%$ \\
\hline Xanthoma & $22 \%$ & $17 \%$ \\
\hline GI bleeding & $17 \%$ & $22 \%$ \\
\hline Ascites & $7 \%$ & $13 \%$ \\
\hline \multicolumn{3}{|l|}{ Liver function tests (normal range) } \\
\hline Bilirubin $(3-20 \mu \mathrm{mol} / \mathrm{l})$ & $21 \cdot 0$ & 23.9 \\
\hline Alkaline phosphatase (3-85 IU/l) & 504 & 502 \\
\hline Alanine aminotransferase (7-40 IU/1) & 72 & 80 \\
\hline Cholesterol (3-8.3 mmol/1) & $6 \cdot 5$ & $6 \cdot 3$ \\
\hline Albumin $(35-50 \mathrm{~g} / \mathrm{l})$ & $35 \cdot 2$ & $35 \cdot 4$ \\
\hline $\operatorname{IgM}(0 \cdot 5-2 \mathrm{~g} / 1)$ & $3 \cdot 5$ & $3 \cdot 6$ \\
\hline Mitochondrial antibodies \% & 88 & 85 \\
\hline \multicolumn{3}{|l|}{ Liver histology } \\
\hline Stage I & $15 \%$ & $12 \%$ \\
\hline Stage II & $37 \%$ & $40 \%$ \\
\hline Stage III & $21 \%$ & $24 \%$ \\
\hline Stage IV & $27 \%$ & $24 \%$ \\
\hline
\end{tabular}

Bilirubin $1 \mu \mathrm{mol} / \mathrm{l}=0.02 \mathrm{mg} / \mathrm{dl}$. Albumin $1 \mathrm{~g} / \mathrm{l}=0.1 \mathrm{~g} / \mathrm{dl}$.

proteinuria (5), thrombocytopenia. (4), gastrointestinal upset (4), rash and arthralgia (3), noncompliance (3) and one each for leucopenia, asthma, pemphigoid, ageusia, psychosis, and palpitations. The final patient was withdrawn when a liver transplant was considered to be indicated. Seven patients were withdrawn from the placebo treated group on account of headaches (2), gastrointestinal upset (1), proteinuria (1), neurological complications (1), non-compliance (1) and liver transplantation (1). Significantly more patients withdrew from the treatment group than the control group $(p<0 \cdot 0001)$ (Table 3$)$.

No significant difference in overall survival between patients in the placebo and d-penicillamine treated groups was observed (Figure); this was independent of whether the total observation period or only the time up to withdrawal was used for calculation of the curves. The $p$ values are calculated after stratification according to each centre, even though the effect of d-penicillamine on survival was not significantly different in the three centres. Separation of the patients into early (histological stage I/II) and late (stage III/IV) showed an apparent beneficial effect on survival when d-penicillamine was used in the early stages of the disease, the mortality rate being one third of that seen in the placebo treated group. The difference, however, did not reach statistical significance $(p=0 \cdot 15)$. None of the patients asymptomatic at entry died during the course of the trial. In patients with late stage disease the death rates were nearly identical in the two groups $(p=0.99)$. Survival in those patients who were able to tolerate the full dose of d-penicillamine was similar to survival in the control group.

The occurrence rate for gastrointestinal bleeding, pruritus (or the need for cholestyramine) and ascites (or use of diuretics) was similar in both groups. The only difference with respect to liver function tests, biochemical, and serological findings was that the use of d-penicillamine was associated with a significant increase in serum alanine aminotransferase, above $136 \mathrm{IU} / \mathrm{l}$. There was no difference in the rate of histological progression as assessed from the

Table 3 Reason for withdrawal from the trial and median time of withdrawal after institution of treatment

\begin{tabular}{|c|c|c|c|c|c|c|}
\hline \multirow[b]{2}{*}{ Cause } & \multicolumn{3}{|c|}{ d-penicillamine } & \multicolumn{2}{|c|}{ Placebo } & \multirow[b]{2}{*}{ (Range) } \\
\hline & No & Time & (Range) & No & Time & \\
\hline Rash & 9 & 4 months & (13 days -7 months) & & & \\
\hline Proteinuria & 5 & 8 months & ( 3 days -24 months) & 1 & 7 months & \\
\hline Thrombocytopenia & 4 & 11 months & (1-19 months) & & & \\
\hline Rash and arthralgia & 3 & 3 months & (1-17 months) & & & \\
\hline Gastrointestinal upset & 4 & 11 months & (2 weeks-18 months) & 1 & 7 months & \\
\hline Leucopenia & 1 & 24 months & & & & \\
\hline Asthma & 1 & $3 \frac{1}{2}$ months & & & & \\
\hline Pemphigoid & 1 & 12 months & & & & \\
\hline Ageusia & 1 & 8 months & & & & \\
\hline Psychosis & 1 & 1 week & . & & & \\
\hline Palpitations & 1 & 3 months & & & & \\
\hline Liver transplantation & 1 & 11 months & & 1 & 7 months & \\
\hline Non-compliance & 3 & 1 month & ( 3 days -8 months) & 1 & 2 weeks & \\
\hline Neurological complications & & & & 1 & 2 months & \\
\hline Headaches & & & & 2 & $3 \frac{1}{2}$ months & (3-4 months) \\
\hline
\end{tabular}



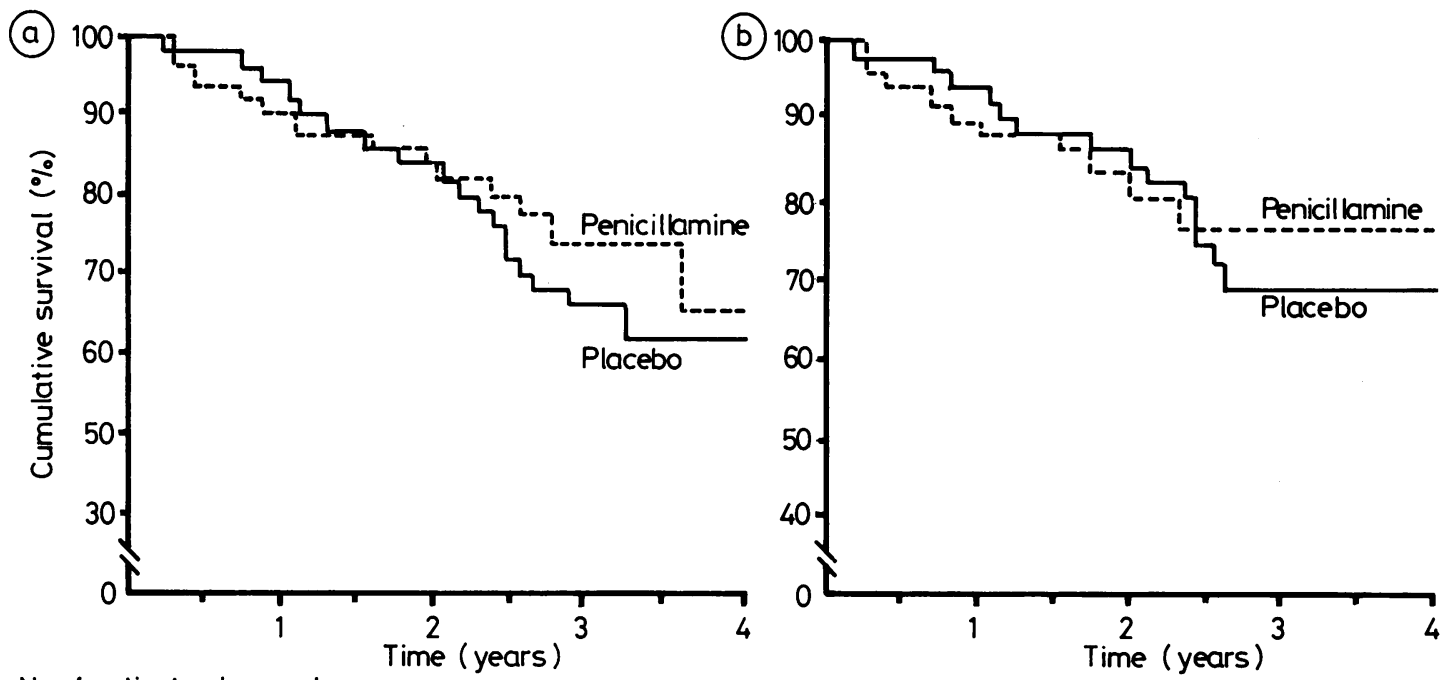

No of patients observed:

$\begin{array}{llllllllllllllllll}\begin{array}{l}\text { Placebo } \\ \text { group 91 }\end{array} & 82 & 71 & 61 & 47 & 36 & 24 & 15 & 10 & 91 & 76 & 65 & 54 & 41 & 31 & 21 & 15 & 10 \\ \begin{array}{l}\text { Penicillamine } \\ \text { group 98 }\end{array} & 82 & 70 & 58 & 44 & 32 & 20 & 12 & 4 & 98 & 69 & 50 & 40 & 27 & 16 & 12 & 8 & 3\end{array}$

Figure Cumulative survival for patients with primary biliary cirrhosis receiving either placebo or d-penicillamine for (a) total period of observation $(O R R=0.91, p=0.78)$ and $(b)$ during period of receiving therapy $(O R R=0.98, p=0.96)$. Number of patients observed in each group represents the number of patients alive at that time.

serial biopsies obtained and d-penicillamine did not appear to prevent progression of the disease from early to late histological stages (Table 1). Analysis of the serological and histological findings in the two groups based on the time until withdrawal gave results similar to those in Table 1 , which are based on the entire period of observation.

Forty patients had died by the time of analysis (Table 4). Of the 18 who died in the d-penicillamine treated group, 16 were associated with liver disease

Table 4 Causes of death in patients entered into the trial

\begin{tabular}{lrc}
\hline & Placebo & d-penicillamine \\
\hline Related to liver disease & 10 & 10 \\
Liver failure & 4 & 4 \\
Liver failure and GI bleeding & 2 & 1 \\
GI bleeding & 1 & - \\
Bacterial peritonitis & 1 & 1 \\
Hepatocellular carcinoma & & \\
Unrelated to liver disease & 1 & - \\
Renal failure & - & 1 \\
Asthma & 1 & - \\
Bronchial cancer & 1 & - \\
Fractured femur & 1 & 1 \\
Cardiovascular disease & 22 & 18 \\
$\quad$ TOTAL &
\end{tabular}

and the remaining deaths were because of preexisting asthma and cardiovascular disease. Of the 22 deaths in the placebo treated group, 18 were associated with liver disease and the remainder were because of cardiovascular disease, renal failure, bronchial carcinoma, and following a fractured femur. There was no significant difference in the number of deaths or distribution of the main causes of death between the two groups.

\section{Discussion}

The use of the occurrence rate ratio to analyse the effect of treatment with d-penicillamine on the survival, clinical, and serological variables was chosen because it is a more effective discriminant of the population trend than measuring the percentage increase or decrease of the variables with time. For example, an increase in serum bilirubin from 8-12 $\mu \mathrm{mol} / \mathrm{l}$ will show the same percentage increase in levels as that from 80 to $120 \mu \mathrm{mol} / 1$. In contrast, with the use of the occurrence rate ratio, only the latter example will be recorded as an 'event' or occurrence. Yet clearly the implications on the natural history of the disease are quite different: levels of serum bilirubin in the normal range are indicative of a good prognosis ${ }^{15}$ whereas the rising 
levels indicate a poor prognosis and advancing disease. ${ }^{16}$ The other advantage of this method of analysis is that it allows for incomplete follow-up of patients for any cause. This method of analysis, however, does require continuous variables to be treated as discrete ones. The arbitrary use of the fifteenth percentile allows a reasonable number of patients to have 'events' recorded. Comparable findings, however, were obtained when different cut-off figures were used. In this report we have analysed results for patients up to the time of withdrawal as well as patients followed during the entire period of the trial. The former analysis may be biased if the patients who were withdrawn from the trial, usually because of drug-related side effects, differ in prognosis from those not withdrawn. Analysis based on the intention to treat may be more valid although the effect of a short and not maintained course of d-penicillamine on the natural history of a disease lasting many years may be questionable. Nonetheless, both methods of analysis gave very similar results.

The various trials of d-penicillamine reported to date differ both in trial design and in dosage used. The largest study is that from the Mayo Clinic ${ }^{13}$ in which patients were given placebo or d-penicillamine $1000 \mathrm{mg}$. There was an associated improvement in survival at all stages of the disease and progression of liver histology from early to late stages was reduced. One death was attributed to side-effects from the drug. In contrast, Epstein et al ${ }^{9}$ used d-penicillamine at a daily dose of $600 \mathrm{mg}$ and found no effect on those treated at early stages, although there was a significant improvement in those treated in histological stages III and IV after 18 months of treatment. In a study carried out in Boston ${ }^{15}$ d-penicillamine was not associated with improvement of any variable measured; indeed, those on active treatment had a slightly worse prognosis. In Newcastle, Bassendine and her colleagues $^{11}$ were able to show that, at a daily dose of $1000 \mathrm{mg}$, there was an improvement in serum transaminase and immunoglobulins, while at lower doses (250 $\mathrm{mg}$ daily) the improvement was only temporary. Survival was not affected compared with placebo in either group. In Sheffield it was found that in doses up to $875 \mathrm{mg}$ daily there was improvement in liver histology, although no effect on survival was found. ${ }^{12}$

To what extent these differences in results are because of selection of patients or different population studied is not clear. It is now becoming apparent that the syndrome of primary biliary cirrhosis covers a wide spectrum of disease activity. It may be possible to identify a subgroup of such patients whose disease activity may be controlled by long term therapy with d-penicillamine, although such identification was not possible in our trial. The mode of action of the drug in primary biliary cirrhosis, if any, is not clear. Although introduced because of its ability to reduce liver copper content and reduce the levels of circulating immune complexes. It is probable that the liver copper is not hepatotoxic in primary biliary cirrhosis: ${ }^{17}$ any improvement noted in patients on treatment with d-penicillamine may not be associated with a reduction in hepatic copper. ${ }^{18}$ Reductions in levels of circulating immune complexes is another probability, but the importance of immune complexes, and indeed their existence in primary biliary cirrhosis, has recently been questioned. ${ }^{19} \mathrm{~d}$-penicillamine and its use requires that the patient attends frequently for blood and urine monitoring. Side effects both in this trial and in the trials reported occurred in up to $30 \%$ of patients.

The maximum period of follow up of patients in the trial is short in comparison with the natural history of the disease. Accordingly, the confidence limits of our results are not very narrow and it is still possible that significant effects on survival will be noted, perhaps in subgroups, when follow-up is longer. For these reasons, it is intended to continue the study although no new patients will be added.

$\mathrm{JN}$ is a senior Wellcome clinical research fellow. We are grateful to the Department of Data Processing at the Rigshospitalet for generous access to the computer and other physicians who released patients for inclusion into the trial. The cooperation of Dr Erik Juhl and Helmer Ring Larsen, Hvidovre Hospital, Copenhagen, is also acknowledged. The supply and distribution of tablets was most efficiently organised through Chemiewerk Hamburg, Frankfurt. We are greatly indebted to Professor Hans Popper, Mount Sinai Hospital, New York, for invaluable assistance with the liver histology.

\section{References}

1 Carman CT, Giansiracusa JE. Effect of steroid therapy on the chemical and laboratory features of primary biliary cirrhosis. Gastroenterology 1955; 28: 193-215.

2 Howat HT, Ralston AJ, Varley H, Wilson JAC. The late results of long-term treatment of primary biliary cirrhosis by corticosteroids. Rev Int Hepatol 1966; 16: 227-38.

3 Sherlock S. Diseases of the liver and biliary system. Oxford: Blackwell, 1981: 227-36. 
4 Crowe J, Christensen E, Smith M et al. Azathioprine in primary biliary cirrhosis. A preliminary report of an international trial. Gastroenterology 1980; 78: 1005-10.

5 Epstein O, Jain S, Lee RG et al. d-penicillamine treatment improves survival in patients with primary biliary cirrhosis. Lancet $1981 ; 1: 1275-7$.

6 Epstein O, de Villiers D, Jain S, Potter W, Thomas HC, Sherlock S. Reduction of immune complexes and immunoglobulins in primary biliary cirrhosis. $N$ Engl $J$ Med 1979; 300: 274-8.

7 Desmukh $\mathrm{K}$, Nimms ME. A defect in the intramolecular and intermolecular cross linking of collagen caused by d-penicillamine. J Biol Chem 1969; 244: 1787-95.

8 Brandt L, Svensson B. Effect of penicillamine on peripheral blood lymphocytes in rheumatoid arthritis. Lancet 1975; 1: 394-5.

9 Jain S, Samourian S, Scheuer PJ, McGee J O'D, Sherlock'S. A controlled clinical trial of d-penicillamine in primary biliary cirrhosis. Lancet $1977 ; 1$ : 831-4.

10 Matloff D, Alpert E, Resnick R, Kaplan M. A prospective trial of d-penicillamine in primary biliary cirrhosis. N Engl J Med 1982; 306: 319-26.

11 Bassendine MF, Macklon AF, Mulcahy R, James O. Controlled trial of high and low dose d-penicillamine in primary biliary cirrhosis. [Abstract] Gut 1982; 23: A909.

12 Triger D, Manifold IH, Cloke P, Underwood JCB. d-penicillamine in primary biliary cirrhosis: two year results. [Abstract] Gut 1980; 21: A919-20.

13 Dickson ER, Fleming CR, Ludwig J. Primary biliary cirrhosis. In: Popper H, Schaffner F, eds. Progress in liver disease, vol 6. New York: Grune and Stratton, 1979: 487-502.

14 Peto R, Pike MC, Armitage $P$ et al. Design and analysis of randomised clinical trial requiring prolonged observation of each patient. II Analysis and example. Br J Cancer 1977; 35: 1-39.

15 Roll JR, Boyer JL, Barry D, Klatskin G. The prognostic importance of clinical and histologic features in asymptomatic and symptomatic primary biliary cirrhosis. $N$ Engl J Med 1983; 308: 1-7.

16 Shapiro J, Smith H, Schaffner F. Serum bilirubin: a prognostic factor in primary biliary cirrhosis. Gut 1979 ; 20: $137-140$.

17 Epstein O, Arborgh B, Sagiv M et al. Is copper hepatoxic in primary biliary cirrhosis? J Clin Pathol 1981; 34: 1071-5.

18 Fleming CR, Lindor KD, Dickson ER, Ludwig J, Baldus WF. d-penicillamine in primary biliary cirrhosis: apparent beneficial effect in spite of a lack of correlation with changes in hepatic copper concentration. [Abstract] Gastroenterology 1978; 75: A964.

19 Goldberg H, Kaplan MM, Mitamuri T et al. Evidence against an immune complex pathogenesis of primary biliary cirrhosis. Gastroenterology 1982; 82: 677-83. 